\title{
Recurrent Congenital Ichthyosis in Newborn: A Case Report
}

\author{
Patil $\mathbf{P}^{1}$, Patil $\mathbf{A}^{2}$, Verma $\mathbf{J}^{3}$, Ghosh $\mathbf{G}^{4}$ \\ ${ }^{1}$ Dr Pooja Patil, Assistant Professor, Department of Obstetrics and Gynecology, L N Medical College, Bhopal, ${ }^{2}$ Dr Abhijit \\ Patil, Assistant Professor, Department of Radiodiagnosis, GMC, Bhopal, ${ }^{3}$ Dr Jyotsna Verma, Assistant Professor, Department \\ of Pediatrics, L N Medical College, Bhopal, ${ }^{4}$ Dr Gopa Ghosh, Consultant, Department of Radiotherapy, L N Medical College, \\ Bhopal
}

Address for correspondence: Dr Pooja Patil, Email: pooja_gynec@yahoo.co.in

\begin{abstract}
Ichthyosis refers to a relatively uncommon group of skin disorders characterized by the presence of excessive amounts of dry surface scales. It can be congenital or acquired. Our patient was third child with this disorder and out of three none survived. In congenital ichthyosis form of disorders, routine histopathology, electron microscopy, and frozen sections of skin biopsy specimens may be required to determine the specific classification of disease. The mainstay of therapy includes removal of surface scales and application of a water barrier. In disabling cases, oral retinoids may reduce cosmetic disfigurement, depression, and social isolation.
\end{abstract}

Keywords: Autosomal Recessive, Congenital ichthyosis, Skin lesion

\section{Introduction}

The term 'ichthyosis' has been derived from the Greek word 'ichthys' meaning fish scale ${ }^{1}$. The severity of symptoms can vary enormously, from the mildest types such as ichthyosis vulgaris which may be mistaken for normal dry skin, to life-threatening conditions such as harlequin type ichthyosis. The most common type of ichthyosis is ichthyosis vulgaris, accounting for more than $95 \%$ of cases $^{2}$. To make a correct diagnosis, age of onset, family history, quality \& distribution of scales, presence or absence of erythroderma, blistering, associated abnormalities of skin and other organ systems involved and histopathology are important ${ }^{3}$.

\section{Case Report}

A 27 year old, multigravida (para 5, live 2) patient admitted with history of eight \& half months amenorrhoea with labour pains with breech presentation. Patient had previous two full term normal deliveries and both babies were normal and alive. Her third and fourth baby delivered at 7 months with skin disorders and both expired in neonatal period. Our case was male live baby

Manuscript received: $11^{\text {th }}$ June 2013

Reviewed: $13^{\text {th }}$ June 2013

Author Corrected; $29^{\text {th }}$ June 2013

Accepted for Publication: $30^{\text {th }}$ June 2013 delivered by assisted vaginal route with breech presentation. He had thick scaly skin, ectropion, eclabium(everted lips) and alopecia called as 'collodion' baby (Image No.1). His Apgar was 6/10 and baby was shifted to NICU for further management. Parents refused treatment and took baby to home against medical advice. Patient came to us for postnatal check up and told that baby died on day $2^{\text {nd }}$ of life.

\section{Discussion}

Ichthyosis is regarded as a disorder of keratinization or cornification, and it is due to abnormal epidermal differentiation or metabolism. The ichthyosiform dermatoses may be classified according to clinical manifestations, genetic presentation ${ }^{4}$ and histologic findings. Inherited and acquired forms of ichthyosis have been described.

Disease Features: Although most neonates with autosomal recessive congenital ichthyosis (ARCI) are collodion babies, the clinical presentation and severity of ARCI may vary significantly, ranging from harlequin ichthyosis, the most severe and often fatal form, to lamellar ichthyosis (LI) and nonbullous congenital ichthyosiform erythroderma (NCIE). 
Harlequin ichthyosis: Harlequin ichthyosis is the most severe form of congenital ichthyosis and is characterized by a profound thickening of the keratin layer of fetal skin and thus covered in thick, hard, armor-like plates of cornified skin separated by deep fissures. The taut skin results in deformation of facial features and microcephaly and contraction abnormalities of the eyes, ears, mouth, and appendages. The term harlequin derived from the newborn's facial expression and the triangular and diamond-shaped pattern of hyperkeratosis. The newborn's mouth is pulled wide open, mimicking a clown's smile.

LI and NCIE: are seemingly distinct phenotypes: classic, severe lamellar ichthyosis (LI) characterized by the presence of large, pigmented scales in the absence of erythroderma $^{5}$ whereas NCIE are with finer whiter scale and underlying generalized redness of the skin.

Ichthyosis vulgaris usually presents within the first year of life; it is characterized by mild ichthyosis/xerosis, keratosis pilaris, and hyperlinear palms and soles, and is often associated with atopy.

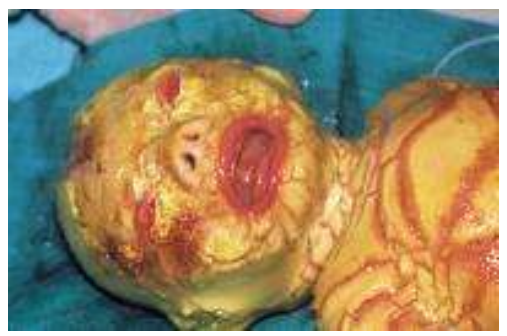

Image No: 1 Ichthyosis fetalis

Acquired ichthyosis may be a marker of various autoimmune disorders, malignancy or concomitant infection with HIV.

\section{Prevalence}

The disease affects all ethnic and racial groups and is seen in higher frequency in populations in which consanguineous marriage is common.

\section{Morbidity/Mortality}

The mortality rate for harlequin ichthyosis is high. With neonatal intensive care and the advent of retinoid therapy, some babies have survived the newborn period. They are still at risk of dying from systemic infection, which is the most common cause of death.

Diagnosis
A physician often can diagnose ichthyosis by looking at the skin. A family history is very useful. In some cases, a skin biopsy is done to help to confirm the diagnosis. In some instances, genetic testing may be helpful in making a diagnosis. Diabetes has not been definitively linked to acquired ichthyosis or ichthyosis vulgaris; however, there are case reports associating new onset ichthyosis with diabetes. ${ }^{6}$

Fetal skin biopsy at approximately 19 weeks may provide an early diagnosis of certain forms of ichthyosis (i.e. Harlequin type, which is extremely severe and usually fatal. $^{7}$

In congenital ichthyosis syndromes, excessive intraamniotic debris and polyhydramnios on ultrasonography scanning in utero may be the first indication of disease.

Other echographic findings may include a persistently open mouth, dense amniotic fluid, and fixed flexion of the extremities.

\section{Management}

For neonates, providing a moist environment, preventing infection by hygienic handling, and treating infection by antibiotics are paramount.

Petrolatum-based creams and ointments are used to keep the skin soft, supple, and hydrated.

Over the first 2 weeks of life, management include careful monitoring of body temperature, hydration and blood electrolytes.

As the child becomes older, keratolytic agents such as alpha-hydroxy acid or urea preparations may be used to promote peeling and thinning of the stratum cornetum.

For individuals with ectropion, lubrication of the cornea with artificial tears or prescription ophthalmic ointments, especially at night, is helpful in preventing dessication of the cornea.

Oral retinoid therapy is recommended for those with severe skin involvement; however, side effects include bone toxicity and ligamentous calcifications from longterm use.

Surgical treatment: When cicatricial ectropion develops despite vigorous skin lubrication, the danger of corneal breakdown and perforation is there. Full-thickness skin grafts from the forearm, post auricular and groin areas may be used to successfully repair the abnormalities. 
Patients must realize that this condition is chronic, and they will need long-term therapy. Without long-term therapy, the defective permeability barrier associated with ichthyosis can result in a chronic loss of water and calories, which may impair growth in children.

\section{References}

1. Inamadar AC, Sacchidanand S,Textbook of Pediatric Dermatology,2009:1:41

2. Okulicz JF, Schwartz RA. Hereditary and acquired ichthyosis vulgaris. International Journal of Dermatology 2003;42(2): 95-8.

3. Thappa DM, Clinical Pediatric Dermatology 2009:1:121.

4. Moeschler JB, Shevell M. Clinical genetic evaluation of the child with mental retardation or developmental delays. Pediatrics 2006;117(6):2304-16.

5. Dhar S, Color Atlas and Synopses of Pediatric Dermatology 2008:2:32-33

6. Scheinfeld N, Libkind M, Freilich S. New-onset ichthyosis and diabetes in a 14-year-old Pediatric dermatology 2001;18(6):501-3.

7. Scott CA, Rajpopat S, Di WL. Harlequin ichthyosis: ABCA12 mutations underlie defective lipid transport, reduced protease regulation and skin-barrier dysfunction. Cell Tissue Res. 2013;351(2):281-8

\section{How to cite this article?}

Patil P, Patil A, Verma J, Ghosh G. Recurrent Congenital Ichthyosis in Newborn: A Case Report. Int J Med Res Rev 2013;1(2):71-73. doi: 10.17511/ijmrr.2013.i02.05 